\title{
PREGNANCY HISTORY AND COGNITION DURING AND AFTER PREGNANCY
}

\author{
T. D. PARSONS \\ E. THOMPSON \\ D. K. BUCKWALTER \\ B. W. BLUESTEIN \\ Fuller Graduate School of Psychology \\ Pasadena, California, USA \\ F. Z. STANCZYK \\ Department of Obstetrics and Gynecology \\ University of Southern California \\ Los Angeles, California, USA
}

\section{J. G. BUCKWALTER}

\section{Southern California Kaiser Permanente Medical Group} Pasadena, California, USA

An increasing body of literature confirms anecdotal reports that cognitive changes occur during pregnancy. This article assessed whether prior pregnancy, which alters a woman's subsequent hormonal environment, is associated with a specific cognitive profile during and after pregnancy. Seven primigravids and nine multigravids were compared, equivalent for age and education. No differences between groups were found during pregnancy. After delivery, multigravids performed better than primigravids on verbal memory tasks. After controlling for mood, a significant difference

Received 1 March 2004.

Address correspondence to J. Galen Buckwalter, $\mathrm{PhD}$, Associate Director of Behavioral and Outcomes Research, Department of Research and Evaluation, Southern California Kaiser Permanente Medical Group, 100 S. Los Robles, 2nd Floor, Pasadena, CA 91101, USA. E-mail: galen.x.buckwalter@kp.org 
in verbal memory remained. A neuroadaptive mechanism may develop after first pregnancy that increases the ability to recover from some cognitive deficits after later pregnancies.

Keywords cognition, postpartum, pregnancy

The dramatic hormonal fluctuations in pregnancy provide a unique opportunity to study the association of cognition to endogenous steroids. A growing body of literature suggests that there are specific cognitive deficits associated with pregnancy. Subjective reports of cognitive dysfunction during pregnancy in 21 out of 51 professional women included forgetfulness, disorientation, confusion, and reading difficulties (Poser et al., 1986). These symptoms were unrelated to age, weight gain, medical symptoms, or mood alterations (Poser et al., 1986). Buckwalter et al. (1999) systematically examined cognitive symptoms and hormone levels during pregnancy and reported a series of cognitive deficits occurring during pregnancy, not attributable to fluctuations in mood, that included more difficulty with verbal learning and with discriminating relevant from irrelevant responses, as well as difficulty on tasks requiring speed of cognitive processing and conceptual tracking (Buckwalter et al., 1999). In this study, performance on indices of verbal memory ranged as low as the 5th percentile during pregnancy (when compared with women of similar age) and only showed a slight improvement after delivery. Hormonal levels of $\mathrm{E}_{2}, \mathrm{~T}$, and DHEA showed no consistent associations with cognition during pregnancy, but after delivery, DHEA showed some associations with better cognitive performance (Buckwalter et al., 1999).

Sharp et al. (1993) found deficits in the recall of word lists, in both primigravid and multigravid pregnant women, when compared to nonpregnant women. This deficit was greater for incidental recall than when the women were explicitly instructed to remember items. Eidelman et al. (1993) found that women in the third month of a high-risk pregnancy performed worse than nonpregnant controls on the ability to recall a short passage of prose, but not on a visual memory task. In a separate group of women with normal pregnancies, deficits in both passage recall and visual memory were reported during the first postpartum day but not during days two and 
three (Eidelman, 1993). The mechanism for any cognitive changes associated with pregnancy remains to he determined.

Not only do hormone levels change around the time of pregnancy, several studies have suggested that having a child affects a woman's subsequent hormonal environment. Dorgan et al. (1995) found that parity modifies age-related endocrine changes, with hormone levels only slightly increasing in nulliparous women and decreasing in parous women. Petrakis et al. (1987) reported that average breast fluid estrogen levels were lower in premenopausal parous women than in nulligravidous or nulliparous women whereas serum estrogen levels did not differ among these three groups. Bernstein et al. (1985) reported that estrogen levels were significantly lower in a sample of 60 parous women compared to 88 nulliparous women, ages 20-40. Musey et al. (1987) have concluded that a first pregnancy induces a long-term alteration in the hormonal environment, an effect that occurs only after a first pregnancy and not after succeeding pregnancies; serum estriol $\left(\mathrm{E}_{2}\right)$ increases significantly whereas serum DHAS and DHA decrease significantly after a first pregnancy.

In addition to long-term hormonal changes, cognitive changes after pregnancy have been reported. For example, Silber et al. (1980), testing women in the 36th week of pregnancy, within 3 days after delivery, and at 3, 6, and 12 months postpartum, found no differences between pregnant women and controls during pregnancy, at the immediate postpartum, or at the 3-month testing. However, the women who had been pregnant showed significant increases in performance on word list learning and reaction time at the 6- and 12month testings, when compared to the controls.

There is evidence that hormones may impact cognition (Couchie \& Kimura, 1991; McCardle \& Wilson, 1990; Nyborg, 1984; Robinson et al., 1994; Sherwin, 1988; Van Goozen et al., 1994). There may be cognitive deficits associated with pregnancy (Buckwalter et al., 1999; Dorgan et al., 1998; Eidelman et al., 1993; Poser et al., 1986; Sharp et al., 1993). Given the long-term hormonal implications of pregnancy (Bernstein et al., 1985; Dorgan et al., 1997; Petrakis et al., 1987), the present authors determined to examine whether the cognitive deficits associated with a subject's current pregnancy were moderated by a previous pregnancy. 
Given the possible general effects of hormones on cognition, hormonal involvement in the cognitive deficits of pregnancy, and the subsequent long-term changes in a woman's hormonal environment after her first pregnancy, the authors determined to investigate whether reproductive history impacts the cognitive performance of women on a battery of neuropsychological tests during pregnancy and alter delivery.

\section{METHODS}

\section{Subjects}

A total of 25 female subjects (mean age $=32.8$, sd $=4.8$; mean education 16.1, $\mathrm{sd}=1.3$ ), were recruited through antepartal classes at a major Los Angeles hospital and through medical practices of Los Angeles area obstetricians. Sixteen subjects completed neuropsychological testing during and after pregnancy and also completed a questionnaire on their reproductive histories. All were fluent in English. MMPI profiles suggested that no subjects exhibited evidence of atypical psychopathology. Subjects were observed to be in good health and had uncomplicated pregnancies and deliveries. All subjects had singleton pregnancies, with 11 girls delivered and 5 boys.

Seven women were undergoing their first pregnancy (mean ago $30.3, \mathrm{sd}=5.3$; mean education $=16.3, \mathrm{sd}=1.3$ ) with nine reporting a previous pregnancy (mean age $=34.7, \mathrm{sd}=3.6$; mean education $=$ 16.0, sd = 1.4). Although 3 women had previous miscarriages, all also had at least 1 live birth. Only 1 of the subjects was not breastfeeding at the time of the second testing.

\section{Procedures}

Research protocol for testing was approved by the University of Southern California Internal Review Board on July 25, 1995. Initially, subjects wore screened via telephone interview to determine eligibility. Inclusion criteria included: absence of major physical and mental health conditions, no anticipation of postnatal surgical 
procedures, and no use of psychotropic medications within one month of testing. All subjects gave written consent to participate. Testing occurred during subject's last month of pregnancy (T1, average 19.8 days prior to parturition) and again one month after delivery (T2, average of 26.5 days post delivery). On the day of testing, a certified phlebotomist obtained blood samples prior to the initiation of testing instruments. Subjects completed a questionnaire on reproductive history and clinical changes associated with pregnancy. Subjects were tested in their residence by 1 of 3 trained neuropsychological testers.

\section{Instruments}

The Test of Nonverbal Intelligence (TONI) measured general intelligence level. The California Verbal Learning Test (CVLT) measured episodic verbal memory. The Boston Naming Test (BNT) measured semantic memory, and the animals test was used to measure verbal fluency and categorical word generation. Digit Span Forward and Backward (Wechsler Adult Intelligence Scale-Revised) measured simple and complex verbal attention and mental control. The Token Test (Boston Diagnostic Aphasia Examination) measured auditory comprehension. Trail-Making Tests A and P and the Stroop Color and Word Test measured executive control. The Judgment of Line Orientation (JLO) was used to evaluate visuoperceptual skills. Standardized alternate forms were used for the CVLT, the JLO, and the TONI to preclude practice effects. The 60-item BNT was separated into 2 separate 30-item tests (used odd and even numbers) to minimize practice effects. Order of form administration was counterbalanced to preclude any systematic effect of form bias. Mood and psychologica1 functioning across occasions was assessed using the Symptom Checklist-90 (SCL-90).

\section{Serum Hormone Assays}

Levels of steroidal hormones commonly associated with cognitive and mood functioning $\left(\mathrm{E}_{2}, \mathrm{P}, \mathrm{T}\right.$, and DHEA), were assayed from blood samples obtained from all subjects. A certified phlebotomist obtained a 10-ml "tiger" top vacutainer prior to testing. The blood 
was transported on ice to the Andrus Gerontology Center at the University of Southern California (USC) where it was centrifuged and the serum removed and frozen at $-75^{\circ} \mathrm{C}$ for later transportation to the Reproductive Endocrine Research laboratory at USC. Radioimmunoassay (RIA) was used to determine hormone levels of estrogen (specifically $\mathrm{E}_{2}$ (Stanczyk et al., 1988), P (Scott et al., 1978), DHEA (Dorgan et al., 1997), and T (Goebelsmann, 1979), as described in previous research. Also see Buckwalter et al. (1999) for a description of the treatment of these serum samples prior to RIA.

\section{Data Analytic Strategy}

Data analyses were conducted with $t$-tests. Demographic variables of age and education were compared for the two groups (primigravid and multigravid women) and found to be equivalent. All neuropsychological tests from $\mathrm{T} 1$ and $\mathrm{T} 2$ were analyzed. Where group differences were significant, it was decided to conduct hierarchical multiple regressions to control for the potentially confounding effects of mood, by forcing the SCL-90 Total score into the equation prior to analyzing the effects of group. The authors used two-tailed significance tests throughout.

\section{RESULTS}

Mean values for the potential confounds of age, education, and mood are provided in Table 1 . See Table 2 for the mean values of hormones assayed before and after delivery: DHEA, T, B, and $\mathrm{E}_{2}$. No significant differences in hormone levels were found between groups.

TABLE 1. Descriptive statistics far potential confounds of age, education, and mood

\begin{tabular}{|c|c|c|c|c|c|}
\hline \multirow[b]{2}{*}{ Variable } & \multicolumn{2}{|c|}{ Primiqravid group } & \multicolumn{2}{|c|}{ Multigravid group } & \multirow[b]{2}{*}{$p$-level } \\
\hline & Mean & $S D$ & Mean & $S D$ & \\
\hline Age & 30.3 & 5.3 & 34.7 & 3.6 & .06 \\
\hline Education & 16.3 & 1.3 & 16.0 & 1.4 & .68 \\
\hline SCL-90 & 56.9 & 44.5 & 43.9 & 30.3 & .49 \\
\hline
\end{tabular}

Note. Primigravid group $(N=7)$; multigravid group $(N=9)$. Mode was assessed using the SCL-90. 
TABLE 2. Mean values of hormones assayed before and after delivery: DHEA, T, P, and $\mathrm{E}_{2}$

\begin{tabular}{lcccccc}
\hline & \multicolumn{2}{c}{ Primigravid group } & & \multicolumn{2}{c}{ Multigravid group } & \\
\cline { 2 - 3 } & $\begin{array}{c}\text { Before } \\
\text { delivery }\end{array}$ & $\begin{array}{c}\text { After } \\
\text { delivery }\end{array}$ & $p$ & $\begin{array}{c}\text { Before } \\
\text { delivery }\end{array}$ & $\begin{array}{c}\text { After } \\
\text { delivery }\end{array}$ & $p$ \\
\hline UHEA & 4.171 & 1.95 & $\mathrm{~ns}$ & 4.3977 & 2.53 & $\mathrm{~ns}$ \\
$\mathrm{E}_{2}$ & .001 & 0.53 & $\mathrm{~ns}$ & .001 & 0.55 & $\mathrm{~ns}$ \\
$\mathrm{P}$ & .0001 & 0.06 & $\mathrm{~ns}$ & .0001 & 0.09 & $\mathrm{~ns}$ \\
$\mathrm{~T}$ & 41.3428 & 7.74 & $\mathrm{~ns}$ & 50.1111 & 8.06 & $\mathrm{~ns}$ \\
\hline
\end{tabular}

Note. Primigravid group $(N=7)$; multigravid group $(N=9)$; ns $=$ not significant.

Hormone levels were subsequently log transformed in order to normalize their distribution curves, thereby enhancing the possibility of detecting marginal associations between hormone level and cognitive performance. Again, no significant differences in log hormone levels were found between groups.

No effect for pregnancy history was found before delivery (T1). However, after delivery (T2), primigravid subjects scored significantly different from multigravid subjects on the CVLT Trials 1 to $5(F(14)=2.38, p=.03)$, Trial $1(F(14)=2.48, p<.03)$, Trial 5 $(F(14)=2.09, p=.05)$, Short Delay Free Recall $(F(14)=2.57, p=$ $.02)$, Short Delay Cued Recall $(F(14)=4.32, p=.001)$, and Long Delay Cued Recall $(F(14)=2.37, p=.03)$. On all the earlier significant measures, mean scores were lower for the primigravid group. No significant difference in performance between groups was found on any neuropsychological measure other than the CVLT. A complete report of test results for primigravid and multigravid women before and after delivery is provided in Table 3. Cognitive tests included in Table 3 are the California Verbal Learning Test (CVLT), Token Test, Animals, Boston Naming Test (PNT), Test of NonVerbal Intelligence (TONI), Trials A and B, Judgment of Line Orientation (JLO), and Stroop Test (Color, Word, and Interference).

After controlling for mood, as described in the section on data analytic strategy, significant differences remained between groups on several subtests of the CVLT, while some formerly significant differences resulted in "trends" toward significance and some lest significance. The subtest un which no significant difference remained 
TABLE 3. Comparison of cognitive test results for primigravid and multigravid women before and after delivery

\begin{tabular}{|c|c|c|c|c|c|c|}
\hline & \multicolumn{2}{|c|}{ Before delivery } & \multirow[b]{2}{*}{$p$} & \multicolumn{2}{|c|}{ After delivery } & \multirow[b]{2}{*}{$p$} \\
\hline & $\begin{array}{l}\text { Primigravid } \\
\text { group }\end{array}$ & $\begin{array}{l}\text { Multigravid } \\
\text { group }\end{array}$ & & $\begin{array}{l}\text { Primigravid } \\
\text { group }\end{array}$ & $\begin{array}{l}\text { Multigravid } \\
\text { group }\end{array}$ & \\
\hline Token & 42.83 & 42.75 & 0.94 & 42.67 & 43.29 & 0.49 \\
\hline Animals & 24.33 & 24.75 & 0.90 & 21.00 & 26.00 & 0.10 \\
\hline BNT & 28.00 & 27.38 & 0.60 & 28.33 & 27.43 & 0.56 \\
\hline TONI & 34.50 & 40.13 & 0.22 & 36.00 & 36.14 & 0.97 \\
\hline Trails A & 24.17 & 19.13 & 0.25 & 32.33 & 23.86 & 0.17 \\
\hline Trails B & $\begin{array}{l}42.67 \\
110.8\end{array}$ & 44.38 & 0.81 & 57.50 & 55.00 & 0.81 \\
\hline Stroop word & 110.83 & 117.75 & 0.53 & 110.17 & 106.57 & 0.62 \\
\hline $\begin{array}{l}\text { Stroop color } \\
\text { Stroop }\end{array}$ & 74.83 & 84.38 & 0.22 & 79.50 & 83.00 & 0.66 \\
\hline interference & 49.50 & 48.38 & 0.84 & 47.83 & 44.86 & 0.63 \\
\hline JLO & 27.83 & 27.13 & 0.64 & 25.50 & 26.86 & 0.47 \\
\hline Digits & 18.17 & 18.13 & 0.99 & 17.00 & 15.14 & 0.49 \\
\hline CVLT total & 55.22 & 54.14 & 0.79 & 54.83 & 62.75 & 0.03 \\
\hline Trial 1 & 7.56 & 7.29 & 0.73 & 6.50 & 8.75 & 0.03 \\
\hline Trial 5 & 12.33 & 11.29 & 0.41 & 11.50 & 14.25 & 0.05 \\
\hline SDFR & 13.22 & 12.29 & 0.45 & 11.67 & 14.50 & 0.02 \\
\hline SDCR & 13.22 & 11.71 & 0.30 & 12.33 & 14.25 & 0.11 \\
\hline LDCR & 13.67 & 12.43 & 0.35 & 12.17 & 14.75 & 0.03 \\
\hline
\end{tabular}

Note. Primigravid group $(N=7)$; multigravid group $(N=9)$. California Verbal Learning Test $=$ CVLT; Boston Naming Test BNT; Test of Non-Verbal Intelligence $=$ TONI; Judgment of Line Orientation $=$ JLO; Short Delay Free Recall $=$ SDFR; Short Delay Cued Recall $=$ SDCR; Long Delay Cued Recall $=$ LDCR.

between groups was Trial $5(p=.15)$. On CVLT Trials $1-5(p=$ $.09)$, Trial $1(p=.06)$, and Long Delay Cued Recall $(p=.09)$, trends toward significance were indicated after controlling for mood. On the Short Delay Free Recall $(p=.05)$ and Short Delay Cued Recall $(p=.001)$ trials, significant differences remained between groups even after controlling for mood, despite the limited statistical power of this study.

\section{DISCUSSION}

Results suggest that the cognitive deficits reported during pregnancy are not related to prior pregnancy history; all subjects are "equally" impaired. However, soon after delivery, our results do suggest that 
women who have previously had children perform better on verbal memory tasks than women who had just given birth for the first time.

It could be intuitively hypothesized that first-time mothers would experience greater stress and anxiety associated with delivery and child care than multigravid women, resulting in greater distraction and poorer performance on neuropsychological tests after delivery, especially the ability to learn and remember new words. Yet when controlling for disturbance in mood, a significant difference in cognitive performance remained between the two groups, with first time mothers performing worse on verbal memory tasks. However, our assessment of the response to the stress of childbirth and the adaptation to the introduction of an infant to the family system is limited. Thus we cannot rule out the presence of a more effective coping strategy as a factor in the better cognitive performance we observe among multigravid women after delivery.

The authors hypothesized that any differences in cognitive performance might be related to differences in the hormonal environment of the subjects. However, the serum levels of DHEA, T, F, and $\mathrm{E}$, for the two groups were statistically equivalent before and after delivery. It is possible that statistical power was not adequate to uncover existing differences in hormone levels between groups. The small sample size may have precluded finding an existing relationship between hormones and cognition, as found in ether studies cited.

Although current results find no obvious hormonal explanation for the difference in cognitive performance between the multi- and primigravid women after delivery, further study is warranted given the limited statistical power. There are also numerous other potentially neuroactive hormones that remain untested. The possibility of hormonal involvement in our findings should not be ruled out. At present, it can be concluded that having a previous child may implicate that women recover more rapidly from specific cognitive deficits associated with pregnancy. Thus, a neuro-adaptive mechanism is suggested.

A possible adaptive mechanism proposed to account for the greater ability of multigravid women to learn new verbal information after delivery may involve the mediation of cholinergic inputs in the brain. 
Sarter and Bruno (1997) hypothesized that cortical acetylcholine (Ach) mediates the cortical processing of "sensory and associational" information. By mediating one's capacity to detect and select environmental stimuli and to allocate appropriate resources to these functions (Sarter \& Bruno, 1997), Ach mediates the encoding and learning of new information, such as information found in the auditory leaning trails of the CVLT. Also, the blockade of cholinergic effects is found to impair the encoding of new input patterns while leaving previously learned inputs patterns untouched (Hasselmo \& Wyble, 1997).

As discussed by Buckwalter et al. (1999), both groups of women in this study demonstrated more difficulty in developing and utilizing an effective verbal learning strategy when pregnant than when not pregnant. Buckwalter et al. discuss the possibility that the ability to learn new verbal information and to discriminate relevant information from irrelevant stimuli, an area of cognition and memory enhanced by increased cholinergic activity (Sarter \& Bruno, 1997; Hasselmo et al., 1996), may be impaired in pregnant women due to "cholinergic dysfunction."

Although this hypothesis needs to be directly assessed in the future, the authors have considered that multigravid women may recover more quickly from cognitive deficits after pregnancy, specifically these deficits related to learning new verbal information, than primigravid women because of some adaptive alteration in the ability of the cholinergic system to rebound from the effects of pregnancy. At present, it is simply interesting to note that the CVLT, the only test to be included in this study that parallels the learning processes mediated by Ach, is the only test in which the two groups were found to differ significantly.

The relationship between hormones and cognition is an exciting and burgeoning area of study, especially as it impacts women over the course of their lives. Although recent findings from the Women's Health Initiative have done much to dash the hopes that exogenous hormone therapy improves cognitive performance or protects against dementia (Shumaker et al., 2003) some role for hormonal exposure in cognition is apparent. Future research is needed to delineate more clearly the nature of this relationship. The hormonal fluctuations associated with naturally occurring reproductive events have largely 
been ignored in research into the cognitive effects of hormonal exposures. The present authors' preliminary findings regarding a possible effect of gravidity on cognition highlight the potential for using reproductive event better to understand the association between hormones and learning and memory. Neuropsychological assessment among larger groups of primigravid and multigravid women appears to have both clinical and research value.

\section{REFERENCES}

Bernstein, L., Pike, M. C., Ross, R. K., Judd, H. L., Brown, J. B., \& Henderson, B. E. (1985). Estrogen and sex hormone-binding globulin levels in nulliparous and parous women. Journal of the National Cancer Institute, 74, 4, 741-745.

Buckwalter, J. G., Stanczyk, F. Z., McCleary, C. A., Bluestein, B. W., Buckwalter, D. K., Rankle, K. P., Chang, L., \& Goodwin, T. M. (1999). Pregnancy, the postpartum, and steroid hormones: Effects on cognition and mood. Psychoneuroendocrinology, 24, 6954.

Dorgan, J. F., Reichman, M. E., Judd, J. T., Brown, C., Longcope, C., Schatzkin, A., Campbell, W. S., Franz, C., Kahle, L., \& Taylor, P. R. (1995). Relationships of age and reproductive characteristics with plasma estrogens and androgens in premenopausal women. Cancer and Epidemiological Biomarkers \& Prevention, 4, 381-386.

Dorgan, J. F., Stanczyk, F. Z., Longcope, C., Stepheson, H. E., Chang, L., Miller, R., Franz, C., Falk, R. T., \& Kahle, L. (1997). Relationship of serum dehydroepiandrosterone (DHEA), DHEA sulfate, and 5-androsterone-3 $\beta, 17 \beta$-diol to risk of breast cancer in postmenopausal women. Cancer and Epidemiological Biomarkers and Prevention, 6, $177-181$.

Eidelman, A. I., Hoffman, N. W., \& Kaitz, M. (1993). Cognitive deficits in women after childbirth. Obstetrics and Gynecology, 81, 764-767.

Espeland, M. A., Shumaker, S. A., Henderson, V. W., Brunner, R. L., Manson, J. E., Gass, M. L., Stefanick, M. L., Lane, D. S., Hays, J., Johnson, K. C., Coker, L. H., Dailey, M., \& Bowen, D. (2003). Effect at estrogen plus progestin on global cognitive function in postmenopausal women: The Women's Health Initiative Memory Study: A randomized controlled trial. JAMA, 289, 2663-2672.

Goebelsmann, U. (1979). Middle and late gestation. In D. R. Mishell \& V. Davajan (Eds.), Reproductive endocrinology, infertility, and conception (pp. 121-134). Philadelphia: F. A. Davis.

Gouchie, C., \& Kimura, D. (1991). The relationship between testosterone levels and cognitive ability patterns. Psychoneuroendocrinology, 16, 4, 323-334.

Hasselmo, M. E., \& Wyble, B. P. (1997). Free recall and recognition in a network model of the hippocampus: Simulating effects of scopolamine on human memory function. Behavioral Brain Research, 89, 1-34.

Hasselmo, M. E., Wyble, B. P., \& Wallenstein, G. V. (1996). Encoding and retrieval at episodic memories: Role of cholinergic and GABAergic modulation in the hippocampus. Hippocampus, 6, 693-708.

McCardle, P., \& Wilson, B. E. (1990). Hormonal influence on language development in physically advanced children. Brain and Language, 38, 410-423.

Musey, V. C., Collins, D. C., Brogan, D. R., Santos, V. R., Musey, P. I., Martino-Saltzman, D., \& Preedy, J. R. K. (1987). Journal of Clinical Endocrinology and Metabolism, 64, 111-118. 
Nyborg, H. (1984). Performance and intelligence in hormonally different groups. Progress in Brain Research, 61, 491-508.

Petrakis, N. L., Wrensch, M. R., Ernster, V. L., Miike, R., Murai, J., Simberg, N., \& Siiteri, P. K. (1987). Influence of pregnancy and lactation on serum and breast fluid estrogen levels: Implications for breast cancer risk. International Journal of Cancer, 40, 587591.

Poser, C. M., Kassirer, M. R., Peyser, J. M. (1986). Benign encephalopathy of pregnancy: Preliminary clinical observations. Acta Neurologica Scandinavica, 73(1), 39-43.

Robinson, D., Friedman, L., Marcus, R., Tinklenberg, J., \& Yesavage, J. (1994). Estrogen replacement therapy and memory in older women. Journal of the American Geriatrics Society, 42, 919-922.

Sarter, M., \& Bruno, J. P. (1997). Cognitive functions of cortical acetylcholine: Toward a unifying hypothesis. Brain Research Review, 23, 28-46.

Scott, J. Z., Stanczyk, F. Z., Goebelsmann, V., \& Mischell, D. R. (1975). A double-antibody radioimmunoassay for serum progesterone using progesterone-3-oximino-[ $\left.{ }^{125}\right]$-histamine as radioligand. Steroids, 31, 393-405.

Sharp, K., Brindle, P. M., Brown, M. W., \& Turner, G. M. (1993). Memory loss during pregnancy. British Journal of Obstetrics and Gynaecology, 100, 209-215.

Sherwin, B. (1988). Estrogen and/or androgen replacement therapy and cognitive functioning in surgically menopausal women. Psychoneuroendocrinology, 13(4), 345-357.

Shumaker, S. A., Legault, C., Thai, L., Wallace, R. B., Ockene, J. K., Hendrix, S. L., Jones, B. N. 3rd, Assaf, A. R., Jackson, R. D., Morley Kotchen, J., Wassertheil-Smoller, S., \& Wactawski-Wende, J. (2003) . Estrogen plus progestin and the incidence of dementia and mild cognitive impairment in postmenopausal women: The Women's Health Initiative Memory Study: A randomized controlled trial. JAMA, 289, 2651-2662.

Silber, M., Almkvist, O., Larsson, B., \& Kerstin, U.-M. (1980). Temporary peripartal impairment in memory and attention and its possible relation to oxytocin concentration. Life Science, 47, 57-65.

Stanczyk, F. Z., Shoupe, D., Nunez, Y., Macias-Gonzales, P., Vijod, M. A., \& Lobo, R. A. (1988). A randomized comparison of normal estradiol delivery in postmenopausal women. American Journal of Obstetrics and Gynecology, 159, 1540-1548.

Van Goozen, S. H. M., Cohen-Kettenis, P. T., Gooren, L. J. G., Frijda, N. H., \& Van De Poll, N. E. (1994). Activating effects of androgens on cognitive performance: Causal evidence in a group al female-to-male transsexuals. Neuropsychologia, 32(10), 11531157.

Van Coozen, S. H. M., Cohen-Kettenis, P. T., Gooren, L. J. G., Frijda, N. H., \& Van De Poll, N. E. (1995). Gender differences in behavior: Activating effects at cross-sex hormones. Psychoneuroendocrinology, 20(4), 343-363.

Yaldo, D. T., Stress, M. E., Fuerst, D. R., \& Ginsburg, K. A. (1998). Explicit memory in pregnancy women. Journal of Obstetrical Gynecology, 179, 731-737. 
Copyright of International Journal of Neuroscience is the property of Taylor \& Francis Ltd and its content may not be copied or emailed to multiple sites or posted to a listserv without the copyright holder's express written permission. However, users may print, download, or email articles for individual use. 